\title{
Counting the cost: The consequences of increased medical malpractice litigation in South Africa
}

We live in uncertain times. The recession in Europe and ongoing political instability in the Middle East are each examples of what could legally be termed a 'statement of fact'. The rising cost of healthcare in South Africa is another fact. This phenomenon is accompanied by an even more disturbing trend: a steep rise in medical malpractice litigation. An important question to consider is what effect this increase is having on healthcare provision in South Africa generally.

Some disturbing statistics have emerged:

- According to the Medical Protection Society (MPS), the cost of reported claims more than doubled over a recent 2-year period. Claims exceeding R1 million have increased by nearly $550 \%$ compared with those of 10 years ago, while claims valued at over R5 million have increased by $900 \%$ in the past 5 years.

- In 2009/2010, the Gauteng Department of Health and Social Development reportedly faced medical malpractice claims totalling R573 million. Media reports of high damages awarded for malpractice in public health institutions are commonplace and becoming more frequent.

- The Health Professions Council of South Africa (HPCSA) received 2403 complaints between April 2011 and March 2012. Many of these related to claims of misdiagnosis, practising outside the scope of practice, and refusal to treat patients.

Whichever way one looks at the situation, there has been a most significant increase in medical malpractice litigation in recent years. Both the size and frequency of claims have escalated, affecting both the public and private sectors. The following is a list of possible causes of the increase in claims:

- A decline in professionalism among healthcare practitioners. In March 2012, the acting CEO of the HPCSA was reported as saying that a decline in the levels of professionalism among practitioners was one reason for the launch of a national radio awareness campaign aimed at educating the public on the role of the HPCSA and to create awareness of patients' rights and responsibilities when accessing healthcare. A decline in professionalism has been offered as an explanation for the increase in claims. Certain commentators hold the opposing view, that increased medical malpractice litigation probably stems from just such an increased public awareness of patient rights coupled with incessant and deliberate marketing by personal injury lawyers eager to capitalise on this awareness.

- Changes in the law. Amendments to the Road Accident Fund (RAF) legislation have made damages claims owing to personal injury sustained in motor vehicle accidents a less lucrative source of work for lawyers who now turn to other types of personal injury litigation such as medical malpractice in pursuit of new revenue streams. This reality can be seen from the numerous television and radio advertisements by traditional RAF lawyers advertising their medical malpractice expertise.

- Technological advances and increased life expectancy affect claim size. Especially evident in so-called 'catastrophic claims' (such as claims for birth defects and brain injuries), the cost of caring for an injured patient for the duration of their life has increased drastically as new technologies have become available to improve the quality of life as well as the life expectancy of such patients. The result is that patient care packages offered or awarded to victims of medical negligence have grown significantly in their capitalised value.
While research into these developments is expected to continue, of immediate concern are the consequences of increased medical malpractice litigation, both for practitioners and their insurers, as well as for public and private healthcare users. The overall impression created by the statistics as well as future projections is that increases in medical malpractice claims contribute to higher medical costs for all patients. The patient has the most to lose if the trend continues, and for the following reasons:

1. An increase in medical malpractice claims has both direct and indirect effects on the cost of healthcare.

- In a direct manner, increased malpractice litigation causes healthcare practitioners' insurance premiums to increase, leading to a hike in fees payable by patients for professional services.

- In smaller urban areas and rural settings, practitioners working in high-risk specialties may not be able to perform enough treatments or surgeries to justify paying increased indemnity insurance premiums. They may decide to move their practice or stop practising altogether. This may well result in a diminution of specialists in those areas, so depriving communities of access to specialist care and expertise.

- Furthermore, an increased risk of litigation may indirectly prompt practitioners to perform additional (often unnecessary) diagnostic and screening tests, which leads to the rendering of medical services to patients of limited or questionable value for the purpose of avoiding adverse outcomes. It can even pre-empt litigation through striving to persuade the legal system that the relevant standard of care was met. This move away from compassion-centred care towards the practice of defensive medicine drives up the cost of healthcare and may even expose patients to unnecessary risk.

2. Further indirect effects are felt when the rampant rise in claims and the increased perception of medical liability risk cause aspirant healthcare professionals, and especially junior doctors, to shy away from certain specialties owing to a fear of the accompanying litigation risk. This factor undoubtedly contributes to a skills shortage in the country, as practitioners lose enthusiasm for the medical profession in general, and particularly in those specialties which are litigation prone.

3. The preceding considerations pose a particular threat to the specialty of obstetrics. By now, it is well known that indemnity subscriptions on behalf of obstetricians are the highest among all medical professionals (although this is not unique to South Africa). Some specialists have chosen to remain uninsured for professional negligence. Regulations providing for compulsory indemnity insurance have been mooted. If followed through, this could cause (or perhaps force) many obstetricians in private practice to stop practising or to change specialties. The only alternative for pregnant mothers would then be to transfer to the public health system for labour and delivery. In the current claims environment, this would cause an explosion of State liability claims. The net effect is negative.

4. There is cause to suggest further that the prevalence of claims has a negative effect on patients' perception of their treating doctors, thus fuelling an already sometimes distrustful relationship between the professional and a patient who consults them for expert advice. 


\section{EDITORIAL}

5. Of concern to everyone should be the effect that increased medical malpractice litigation has on the State's ability to finance healthcare, which is already tenuous in the setting of an overburdened health system such as ours. The problem of limited resources available to meet the needs of the overwhelming majority of the population who rely on public health institutions has always existed but is now becoming extreme owing to the increase in the number and value of medical negligence claims having to be paid. The additional burden of having to find money within provincial health departmental budgets to pay claims together with legal costs threatens to further destabilise the public health system. Ultimately, it falls to the taxpayer to foot the bill for malpractice claims against the State, regardless of whether or not these are due to inadequate resourcing or decreasing levels of professionalism among healthcare practitioners.

In summary, the rise in medical malpractice claims has been exponential in recent years. Serious concerns are being raised regarding the sustainability of the current claims trajectory, not just for practitioners or their patients but also the wider healthcare economy. Increased litigation is pushing up the cost of professional indemnity insurance, resulting in higher medical costs in the private sector. Increased malpractice litigation against public health institutions, especially in catastrophic claims amounting to millions of Rands, affects the State's ability to finance healthcare in the medium to long term, has a negative effect on service delivery, and ultimately hits the taxpayer. On a personal level, many healthcare practitioners are struggling to reconcile their ethical duties towards patients with a growing aversion to liability risk and the related fear of being sued. This fear leads to many engaging in defensive practices that affect the cost and quality of health interventions.

Some good news is that both industry and government are keenly aware of the real and present need to change the claims situation. Both have committed to identifying ways of curbing the tide in medical malpractice claims and litigation as well as in implementing measures aimed at reinforcing defined standards of care, managing patient expectations and outcomes, and improving patient experience through better communication and more education.

The shared hope of all stakeholders is that the current effects of the rise in medical malpractice claims can be off-set by timeous intervention and a co-ordinated approach to preserve the stability and ensure the sustainability of healthcare in the future.

Acknowledgement. This discussion is based on a conference paper delivered by the author at the annual Norton Rose Medical Law Seminar in Johannesburg on 23 August 2012.

\section{J Malherbe}

Norton Rose South Africa, Johannesburg

Corresponding author: J Malherbe (justin.malherbe@nortonrose.com)

S Afr Med J 2013;103(2):83-84. DOI:10.7196/SAMJ.6457 